\title{
ADP-Ribosylation Factor 6 Regulates Actin Cytoskeleton Remodeling in Coordination with Rac1 and RhoA
}

\author{
RITA L. BOSHANS, ${ }^{1}$ STACEY SZANTO, ${ }^{1}$ LINDA vAN AELST, ${ }^{2}$ AND CRISLYN D’SOUZA-SCHOREY ${ }^{1,3 *}$ \\ Department of Biological Sciences ${ }^{1}$ and Walther Cancer Institute, ${ }^{3}$ University of Notre Dame, \\ Notre Dame, Indiana, and Cold Spring Harbor Laboratory, Cold Spring Harbor, New York ${ }^{2}$
}

Received 6 October 1999/Returned for modification 16 November 1999/Accepted 22 February 2000

\begin{abstract}
In this study, we have documented an essential role for ADP-ribosylation factor 6 (ARF6) in cell surface remodeling in response to physiological stimulus and in the down regulation of stress fiber formation. We demonstrate that the G-protein-coupled receptor agonist bombesin triggers the redistribution of ARF6- and Rac1-containing endosomal vesicles to the cell surface. This membrane redistribution was accompanied by cortical actin rearrangements and was inhibited by dominant negative ARF6, implying that bombesin is a physiological trigger of ARF6 activation. Furthermore, these studies provide a new model for bombesininduced Rac1 activation that involves ARF6-regulated endosomal recycling. The bombesin-elicited translocation of vesicular ARF6 was mimicked by activated Goq and was partially inhibited by expression of RGS2, which down regulates $\mathrm{Gq}$ function. This suggests that $\mathrm{Gq}$ functions as an upstream regulator of ARF6 activation. The ARF6-induced peripheral cytoskeletal rearrangements were accompanied by a depletion of stress fibers. Moreover, cells expressing activated ARF6 resisted the formation of stress fibers induced by lysophosphatidic acid. We show that the ARF6-dependent inhibition of stress fiber formation was due to an inhibition of RhoA activation and was overcome by expression of a constitutively active RhoA mutant. The latter observations demonstrate that activation of ARF6 down regulates Rho signaling. Our findings underscore the potential roles of ARF6, Rac1, and RhoA in the coordinated regulation of cytoskeletal remodeling.
\end{abstract}

The ADP-ribosylation factor (ARF) proteins comprise a group of five Ras-related GTPases that are thought to function as regulators of membrane traffic. In vitro, the ARF proteins function as cofactors in the cholera toxin-catalyzed ADP-ribosylation of Gs $(21,36)$, hence its name, and have also been shown to stimulate the activity of phospholipase D (4, 6, 16, 25, 31). ARF1 has been extensively investigated; it is localized to the Golgi apparatus and plays a critical role in the recruitment of coat proteins during the formation of transport vesicles, a process critical for maintaining the integrity of the secretory pathway (37). Recently, much attention has been focused on ARF6, the least-conserved ARF protein that shares $66 \%$ amino acid homology with ARF1. ARF6 is localized to the plasma membrane and endosomes depending on its nucleotide status and has been shown to regulate endocytic traffic at the cell periphery $(8,42,45)$.

Immunoelectron microscopy observations in $\mathrm{CHO}$ cells have revealed that expression of the GTP-bound constitutively activated mutant of ARF6, ARF6(Q67L), induced an elaboration of the plasma membrane and a depletion of recycling endosomal vesicles. In contrast, the expression of the dominant negative mutant of ARF6, ARF6(T27N), resulted in sequestration of ARF6 in the perinuclear recycling endosome, the distribution of which partially overlapped with that of transferrin receptors and cellubrevin (10). These findings, together with the observation that ARF6(T27N) expression inhibited the recycling of ligands to the plasma membrane, led to the speculation that nucleotide exchange of ARF6 triggered the redistribution of endosomal membrane to the cell surface $(8$, 10, 45). The ARF6-induced redistribution of endosomal membrane was accompanied by a rearrangement of the cortical

\footnotetext{
* Corresponding author. Mailing address: Department of Biological Sciences, Galvin Life Science Building, University of Notre Dame, Notre Dame, IN 46556-0369. Phone: (219) 631-3735. Fax: (219) 6317413. E-mail: D’Souza-Schorey.1@nd.edu.
}

actin cytoskeleton $(9,44)$. In CHO cells, expression of ARF6 induced the formation of actin-rich microvillus-like protrusions at the cell surface and a depletion of stress fibers (9). These actin rearrangements were distinct from those induced by the expression of activated mutant forms of the Rho family GTPases Cdc42, Rac1, and RhoA.

The Rho family GTPases regulate the assembly and organization of the actin cytoskeleton and have more recently also been implicated in the regulation of transcriptional activation, cell cycle progression, and cell transformation $(15,53)$. In fibroblasts, activation of Cdc42 and Rac results in the formation of filopodia and lamellipodia, respectively $(23,39,48)$, whereas Rho activation induces the formation of stress fibers (49). These GTPases may also function in a hierarchical signaling cascade in which the activation of $\mathrm{Cdc} 42$ leads to the activation of Rac, which in turn activates Rho (38).

We had previously shown that ARF6-mediated peripheral actin rearrangements were regulated by POR1, a Rac1-interacting protein that plays a role in Rac1-induced membrane ruffling $(9,53)$. As previously observed for Rac1, ARF6 in its GTP-bound conformation interacted with POR1 and deletion mutants of POR1 blocked ARF6-mediated cytoskeletal rearrangements. The dominant negative mutants of either GTPase, ARF6 or Rac1, did not interfere with actin rearrangements mediated by the other, which lead us to conclude that ARF6 and Rac1 functioned in parallel rather than on a linear signaling pathway. In addition to interacting with POR1, Rac1 and ARF6 have been implicated in regulated secretion in mast cells and adrenal chromaffin cells, respectively $(13,41)$, and they both inhibit receptor-mediated endocytosis $(8,26)$. More recently, it was demonstrated that Rac1 colocalized with ARF6 in a perinuclear recycling compartment in HeLa cells and that pharmacological agents such as aluminum fluoride (AlF) shifted the distribution of vesicle-associated ARF6 and Rac1 to the plasma membrane (46). These findings suggest that actin rearrangements induced by ARF6 and Rac1 are coupled to 
movement of intracellular membrane-associated ARF6 and Rac1 to the plasma membrane. Several observations support the contention that exit sites of recycling endosomal membrane at the cell surface are polarized and that this membrane recycling is coupled to the formation of actin-based structures at the leading edge $(2,20,28)$. Furthermore, studies have shown that endosomal membrane recycling appears to be promoted or enhanced by a physiological stimulus. Treatment of $\mathrm{KB}$ cells with epidermal growth factor resulted in the formation of membrane ruffles that are enriched in endosomal ligands such as transferrin receptors (3). Various growth factors and bioactive lipids induce cytoskeletal rearrangements by activation of the Rho family GTPases. For example, membrane ruffling induced by platelet-derived growth factor (PDGF), insulin, and bombesin is mediated by the Rac1 GTPase $(18,39$, 49), whereas lysophosphatidic acid and bombesin induce stress fiber formation via the activation of Rho (48). Given our previous observations that activated ARF6 induces rearrangements of the cortical actin cytoskeleton, we were interested in determining whether ARF6 mediates actin remodeling triggered by one or more extracellular agonists.

In this study, we report that the G-protein-coupled agonist bombesin triggers the redistribution of endosomal ARF6 and Rac1 to the plasma membrane, resulting in peripheral actin rearrangements. The bombesin-induced recruitment of vesicle-associated ARF6 and Rac1 to the plasma membrane was dependent on ARF6 activation. Furthermore, we show that activated $\mathrm{Gq}$ mimicked the effect of bombesin by promoting the translocation of ARF6 to the cell surface, suggesting that $\mathrm{Gq}$ functions as an upstream regulator of ARF6 activation. The ARF6-induced peripheral rearrangements were accompanied by a diminution of stress fibers. Moreover, cells expressing activated ARF6 did not exhibit stress fiber formation upon treatment with LPA (lysophosphatidic acid). We show that this ARF6-dependent decrease in stress fiber formation in response to LPA was due to an inhibition of RhoA activation. Thus, while ARF6 functions in concert with Rac1 to enhance membrane ruffling, the ARF6 and Rho pathways appear to be antagonistic.

\section{MATERIALS AND METHODS}

Cells, plasmids, antibodies, and reagents. TRVb-1 cells, a $\mathrm{CHO}$ (Chinese hamster ovary) cell line that overexpresses transferrin receptors (31), were grown and maintained in Ham's F-12 medium (Gibco-BRL, Grand Island, N.Y.) supplemented with $5 \%$ fetal bovine serum (FBS), penicillin-streptomycin, and 100 $\mu \mathrm{g}$ of G418 per ml. Mammalian expression plasmids encoding wild-type and mutant derivatives of ARF6, Rac1, and RhoA that were used in this study have been previously described $(8,9,11)$. To generate hemagglutinin (HA)-tagged ARF6, wild-type ARF6 cDNA was amplified by PCR by using a 5' primer containing an $X b a$ I restriction site and N-terminal sequence of ARF6 and a 3' primer containing an $X b a \mathrm{I}$ restriction site, the HA epitope, and the C-terminal sequence of ARF6. The PCR product was subcloned into the XbaI site of pcDNA3-1 (Clontech). Sequence and orientation was confirmed by DNA sequencing. Mammalian expression plasmids encoding $\mathrm{G} \alpha \mathrm{q}(\mathrm{R} 183 \mathrm{C})$ and RGS2 were generously provided by Ken Blumer (Washington University) and Gai3(Q204L) was kindly provided by Maurine Linder (Washington University). Bacterial expression plasmid RBD (Rho binding domain)-pGEX, was kindly provided by Martin Schwartz (Scripps Research Institute). C1199Tiam1:pCDNA and antiTiam 1 polyclonal antibodies were generous gifts from John Collard and Frank van Leeuwen (Netherlands Cancer Institute). For Rac1 localization studies, affinity-purified anti-Rac1 mouse monoclonal antibody (Transduction Laboratories, Lexington, Ky.) and anti-Rac1 peptide rabbit polyclonal antibodies (Santa Cruz Biotechnology, Inc., Santa Cruz, Calif.) were used. ARF6 was localized by using an affinity-purified anti-ARF6 antisera previously described (8). Affinitypurified anti-Gq polyclonal antibody was from Santa Cruz Biotechnology, Inc. Fluorescein and Rhodamine-conjugated donkey anti-rabbit and donkey antimouse anti-immunoglobulin $\mathrm{G}$ was purchased from ICN, Costa Mesa, Calif. Anti-HA and anti-FLAG epitope monoclonal antibodies were from Boehringer Mannheim Biochemicals, Indianapolis, Ind., and Kodak IBI, respectively. Rhodamine phalloidin was from Molecular Probes, Eugene, Oreg. Exoenzyme C3 transferase and PDGF- $\beta$ were from Calbiochem-Behring, La Jolla, Calif. LPA, bombesin, and all other chemicals were obtained from Sigma Chemical Co., St. Louis, Mo.

Expression of ARF6 and Rac1 proteins by using the Sindbis virus expression system. ARF6 and Rac1 proteins were expressed in TRVb-1 cells when the Sindbis virus was used as an expression vector. Recombinant virus encoding ARF6 and its mutant derivatives were generated as previously described (8). A virus titer of $50 \mathrm{PFU} / \mathrm{cell}$ was used for cell infection. Adsorption was conducted at room temperature for $1 \mathrm{~h}$ in $250 \mu \mathrm{l}$ of phosphate-buffered saline (PBS) containing $1 \%$ FBS. The infection mixtures were replaced by $2 \mathrm{ml}$ of Ham's F-12 medium containing $3 \% \mathrm{FBS}$, and cells were maintained at $37^{\circ} \mathrm{C}$. Experiments were performed $4 \mathrm{~h}$ postinfection. For examination of protein expression, cells were lysed in $1 \%$ sodium dodecyl sulfate (SDS). Cell lysates were analyzed by SDS-polyacrylamide gel electrophoresis (PAGE), were transferred to nitrocellulose membranes, and were blotted for ARF6 and/or Rac by using monoclonal antibodies directed against ARF6 and Rac1 (Transductions Laboratories), respectively. ARF6 and Rac wild-type and mutant proteins migrated as $20-\mathrm{kDa}$ bands (data not shown), and the level of protein expression was approximately fivefold higher than endogenous levels.

Fluorescence microscopy procedures. $\mathrm{CHO}$ cells on coverslips were fixed with $2 \%$ paraformaldehyde for $30 \mathrm{~min}$, were permeabilized, and were quenched with PBS containing $0.05 \%$ Triton $\mathrm{X}-100,0.1 \mathrm{~N} \mathrm{NH} \mathrm{Nl}_{4}$, and $0.2 \%$ gelatin. After permeabilization, cells were first incubated with appropriate primary antibodies for $2 \mathrm{~h}$ at room temperature. Cells were washed and then incubated with fluorophore-conjugated secondary antibodies with or without rhodamine phalloidin. Cells were mounted in $70 \%$ glycerol (in PBS) and were visualized by using a Zeiss axiovert microscope and a Bio-Rad confocal scanning imaging system.

Electroporation procedures. Expression plasmids ARF6(Q67L)-pCDNA3-1 and Rho(G14V)-pCGT, or HA-tagged ARF6-pCDNA3-1 and G $\alpha$ q(R183C)PCMV5 or Goi3(Q204L)-PC15, or ARF6-pCDNA3-1 and RGS2-PEGFP-C1 were transected into TRVb-1 cells by electroporation by using a Bio-Rad cell electroporator according to the manufacturer's instructions. Briefly, $3 \times 10^{6}$ exponentially growing cells were trypsinized and suspended in a total volume of $400 \mu \mathrm{l}$ of PBS containing $15 \mu \mathrm{g}$ of each plasmid DNA. Cells were electroporated at $260 \mathrm{~V}$ and $960 \mathrm{mF}$. Electroporated cells were suspended in $2 \mathrm{ml}$ of growth medium, were seeded on glass coverslips, and were analyzed for protein expression and actin filament rearrangements 24 to $36 \mathrm{~h}$ after transfection.

Cell microinjection. Cells on coverslips were microinjected by using a Narashigie microinjection system according to the manufacturer's instructions with 0.3 $\mathrm{mg}$ of ARF6(Q67L) per ml alone or along with $100 \mu \mathrm{g}$ of exoenzyme C3 transferase per ml. Following injection, cells were incubated in growth media at $37^{\circ} \mathrm{C}$. At 2 to $2.5 \mathrm{~h}$ postinjection, cells were fixed and processed for indirect immunofluorescence microscopy. Recombinant ARF6(Q67L) used for these studies was expressed in BL21-DE3 bacteria cotransfected with bacterial expression plasmids encoding ARF6(O67L) and $n$-myristoyltransferase (kindly provided by Richard Klausner, National Institutes of Health) as previously described (8). myrARF6(Q67L) was purified as previously described (30).

GTP loading of ARF6 in intact cells. CHO cells $\left(10^{6}\right)$ were transfected with 15 $\mu \mathrm{g}$ of HA-tagged ARF6 plasmid DNA by using electroporation and were seeded into three wells of a six-well tissue culture plate. Cells were maintained at $37^{\circ} \mathrm{C}$ for $24 \mathrm{~h}$ in growth media, after which the media were replaced by serum-free and phosphate-free media containing $250 \mu \mathrm{Ci}$ of $\left[{ }^{32} \mathrm{P}\right]$ orthophosphate per $\mathrm{ml}$ for $16 \mathrm{~h}$. Preparation of cell lysates and immunoprecipitation of bound ARF6 was performed as described by Langille et al. (27), except that anti-HA monoclonal antibody was used for immunoprecipitation. Elution and separation of bound nucleotides by thin-layer chromatography was carried out as described (27). Chromatography plates were subjected to autoradiography.

MAPK and JNK assays. For monitoring activation by mitogen-activated protein kinase (MAPK), CHO cells were cotransfected (by lipofectamine method) with $5 \mu \mathrm{g}$ of HA-tagged $\mathrm{p} 42^{\mathrm{MAPK}}$ and $5 \mu \mathrm{g}$ of vector pcDNA3-1, HRasV12pcDNA3-1, ARF6(Q67L)-pcDNA3-1, or ARF6(T27N)-pcDNA3-1. After an 8-h incubation with the complexes, cells were incubated in 5\% FBS-containing media for $16 \mathrm{~h}$ and then were incubated for $12 \mathrm{~h}$ in serum-free media. Cells were treated with or without bombesin $(0.2 \mu \mathrm{M})$ for $10 \mathrm{~min}$ at $30^{\circ} \mathrm{C}$. Cells were then lysed and immunoprecipitated with anti-HA monoclonal antibody 12CA5. Immune complexes were collected by binding to protein A-Sepharose, were washed extensively with lysis buffer, and then were incubated for $30 \mathrm{~min}$ at $30^{\circ} \mathrm{C}$ in kinase assay buffer (20 mM Tris [pH 7.4], $20 \mathrm{mM} \mathrm{MgCl}, 2 \mathrm{mM} \mathrm{MnCl}_{2}, 1 \mathrm{mM} \mathrm{Na}_{3} \mathrm{VO}_{4}, 20$ $\mu \mathrm{M}$ ATP) and $10 \mu \mathrm{Ci}$ of $\left[\gamma^{-32} \mathrm{P}\right] \mathrm{ATP}$, with $0.2 \mathrm{mg}$ of myelin basic protein per $\mathrm{ml}$ as a substrate. The reaction products were analyzed by SDS-PAGE and were visualized by autoradiography. The presence of immunoprecipitated HA-MAPK was assessed by using anti-HA monoclonal antibody 12CA5. Expression of ARF6 and Ras proteins was verified by using polyclonal antibody against ARF6 and anti-HA monoclonal antibody $12 \mathrm{CA} 5$ for Ras. For measurements of c-Jun Nterminal kinase (JNK) activity, $\mathrm{CHO}$ cells were cotransfected with $5 \mu \mathrm{g}$ of HA-tagged JNK and $5 \mu \mathrm{g}$ of vector pcDNA3-1, ARF6(T27N)-pcDNA3-1, RacV12-pcDNA3-1, ARF6(Q67L)pcDNA3-1, RacV12-pcDNA3-1 plus vector, or RacV12-pcDNA3-1 plus ARF6(T27N)-pcDNA3-1. After an 8-h incubation with the complexes, cells were incubated in 5\% FBS-containing media for $16 \mathrm{~h}$ and were then incubated for $12 \mathrm{~h}$ in serum-free media. Cells were treated with or without epidermal growth factor (EGF) $(50 \mathrm{ng} / \mathrm{ml})$ for $20 \mathrm{~min}$ at $30^{\circ} \mathrm{C}$. Following cell lysis, JNK1 was immunoprecipitated with anti-HA monoclonal antibody $12 \mathrm{CA} 5$, and immune complexes were collected by binding to protein 

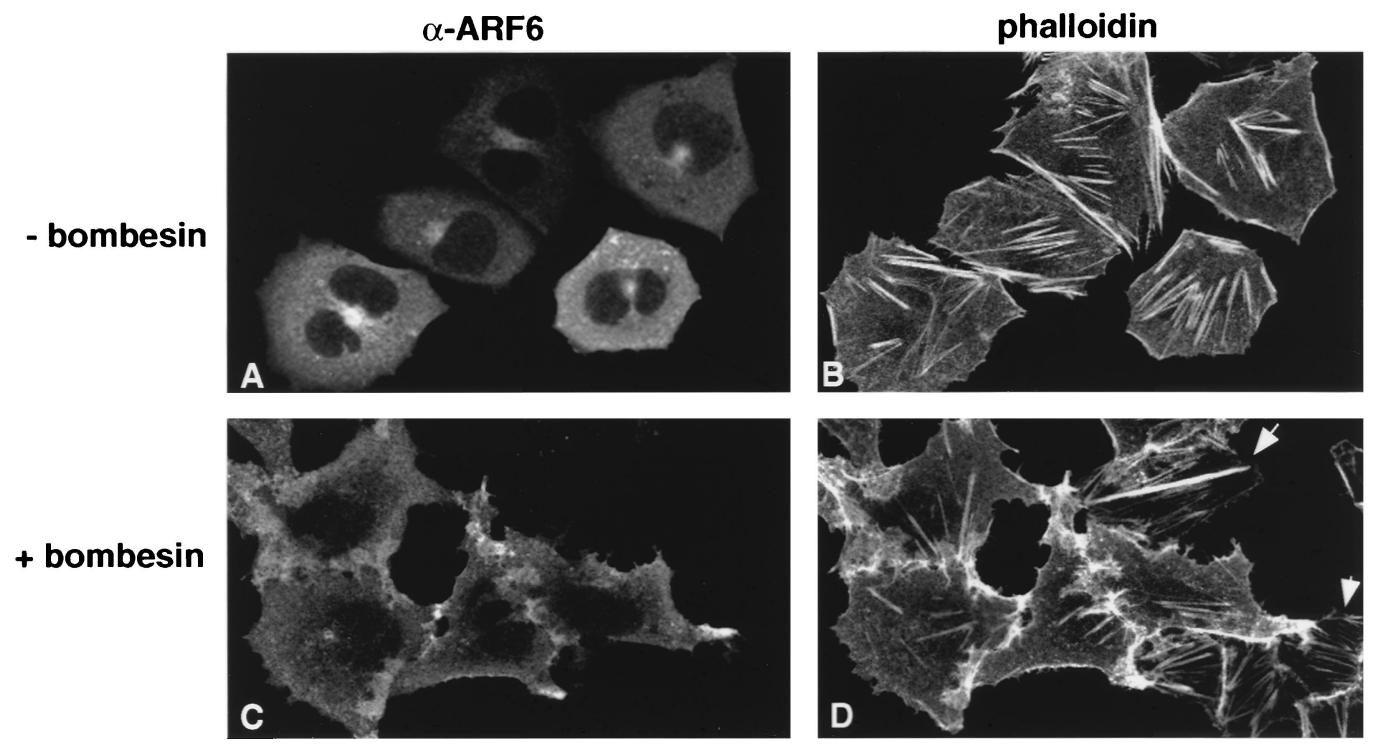

FIG. 1. Bombesin promotes ARF6 activation. (A to D) Bombesin redistributes ARF6 from perinuclear vesicles to the plasma membrane. Cells transfected with wild-type ARF6 were treated without (A and B) or with (C and D) $15 \mathrm{nM}$ bombesin for $15 \mathrm{~min}$ at $37^{\circ} \mathrm{C}$. Cells were fixed and labeled with affinity-purified anti-ARF6 polyclonal antibody and were processed for immunofluorescence microscopy. Cytoskeletal rearrangements were visualized by rhodamine phalloidin staining. Untransfected cells in panel D that exhibit stress fibers are indicated by arrows. (E) GTP loading of ARF6 in intact cells. CHO cells treated with or without bombesin or EGF as indicated were transfected with HA-tagged ARF6 and were labeled with $\left[{ }^{32} \mathrm{P}\right]$ orthophosphate. ARF6 was immunoprecipitated with anti-HA monoclonal antibody, and bound nucleotides were eluted, separated by thin-layer chromatography, and subjected to autoradiography. The data shown are representative of three separate experiments.

A-Sepharose and were incubated with glutathione $S$-transferase (GST)-N-terminal c-Jun $\left(3 \mu \mathrm{g} /\right.$ reaction) in kinase assay buffer for $30 \mathrm{~min}$ at $30^{\circ} \mathrm{C}$. The reaction products were analyzed by SDS-PAGE and were visualized by autoradiography. Immunoprecipitated HA-tagged JNK was determined by using anti-HA monoclonal antibody 12CA5. The expression of Rac1 and ARF6 proteins was confirmed by using polyclonal antibodies against Rac1 and ARF6, respectively.

RBD-GST in vitro binding assay. CHO cell lysates were washed with ice-cold media without serum and were lysed in buffer A (50 mM Tris- $\mathrm{HCl}$ [pH 7.2], $0.8 \%$ Triton, $0.1 \%$ SDS, $500 \mathrm{mM} \mathrm{NaCl}, 10 \mathrm{mM} \mathrm{MgCl}_{2}$, and $10 \mu \mathrm{g}$ of protease cocktail per $\mathrm{ml}$ [Sigma]). Cell lysates were centrifuged at $14,000 \times g$ at $4^{\circ} \mathrm{C}$ for $10 \mathrm{~min}$. Equal volumes of supernatant were incubated with GST-Rho-binding domain (RBD) immobilized on glutathione-Sepharose on ice for $90 \mathrm{~min}$. The resin was washed extensively with buffer B (Tris- $\mathrm{HCl}[\mathrm{pH} 7.0], 0.8 \%$ Triton, $150 \mathrm{mM} \mathrm{NaCl}$, $10 \mathrm{mM} \mathrm{MgCl} 2,10 \mu \mathrm{g}$ of protease cocktail per ml). The washed resin was boiled in SDS-PAGE sample buffer, and bound proteins were resolved on SDS gels followed by Western blot analysis by using anti-RhoA polyclonal antibodies (Santa Cruz Biotechnology).

\section{RESULTS}

Endosomal ARF6 translocates to the plasma membrane in response to physiological stimulus. The Rho GTPases couple plasma membrane receptors with actin rearrangements induced by specific growth factors and other extracellular agonists $(23,39,48)$. For instance, Rac1 is required for PDGFstimulated actin polymerization at the cell surface that leads to the formation of membrane ruffles, whereas LPA-induced stress fiber formation is mediated by activation of Rho. To identify extracellular stimuli that induced ARF6 activation, cells expressing wild-type ARF6 were treated with various physiological agonists, were fixed, and were labeled with antiARF6 antibody and with rhodamine phalloidin to view actin filament distribution. Consistent with our prior observations,

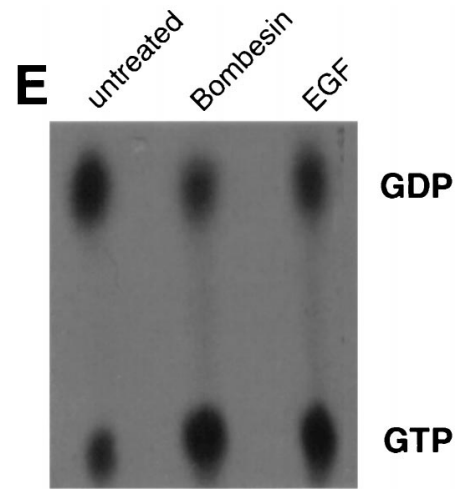

wild-type ARF6 localized predominantly to a perinuclear recycling endosomal compartment and had no effect on surface remodeling (10). Treatment of quiescent $\mathrm{CHO}$ cells with the G-protein-receptor-coupled agonist bombesin induced the redistribution of ARF6 from perinuclear endosomes to the cell surface (Fig. 1A and C). The translocation of vesicular ARF6 to the cell surface was accompanied by surface rearrangements of the actin cytoskeleton that resembled those induced by the expression of ARF6(Q67L), the plasma-membrane-associated and GTP-bound mutant of ARF6 (Fig. 1D). The bombesinelicited translocation of endosomal vesicles and cytoskeletal rearrangements was blocked by expression of ARF6(T27N), the endosome-associated dominant negative mutant of ARF6 (data not shown). These results indicate that bombesin is a physiological trigger that elicits the redistribution leading to peripheral actin rearrangements. The redistribution of ARF6 to the cell periphery was also seen when cells were treated with EGF, although this response was not as dramatic as that seen with bombesin treatment (data not shown). In contrast, treatment of cells with PDGF, insulin, and LPA induced actin rearrangements (membrane ruffles and stress fibers, respectively) but had only a slight effect on the redistribution of vesicle-associated ARF6 to the plasma membrane (data not shown). We are presently testing other extracellular agonists for their ability to redistribute vesicle-associated ARF6 to the plasma membrane.

Next, we assessed whether stimulation of cells with bomb- 

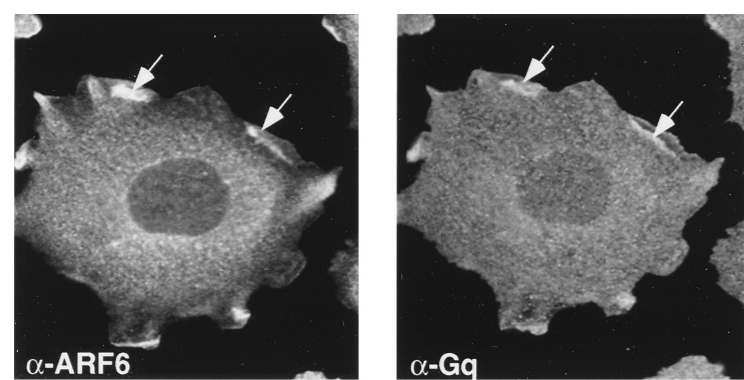

$A R F 6+G q(R 183 C)$

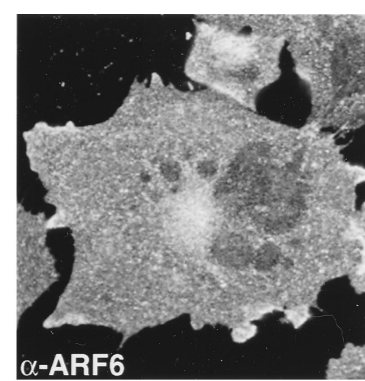

ARF6 + RGS2

FIG. 2. Effect of G $\alpha \mathrm{q}(\mathrm{R} 183 \mathrm{C})$ and RGS2 on ARF6 distribution. Cells cotransfected with plasmids encoding HA-tagged wild-type ARF6 and G $\alpha \mathrm{q}(\mathrm{R} 183 \mathrm{C})$ were fixed and labeled with anti-HA monoclonal antibody (left) and affinity-purified anti-G $\alpha$ q polyclonal antibody (middle) and were processed for immunofluorescence. Cells cotransfected with plasmids encoding ARF6 and RGS2-GFP were treated with 15 nM bombesin for 15 min and were fixed and labeled with anti-ARF6 antibody (right). RGS2 expression was monitored by GFP (data not shown). Wild-type ARF6 and G $\alpha$ q colocalize at the cell surface (arrows), whereas coexpression of RGS2 inhibits the redistribution of ARF6 to the plasma membrane.

esin and EGF increased the levels of ARF6-GTP. For these studies, cells were transfected with HA-epitope-tagged ARF6 and were labeled with $\left[{ }^{32} \mathrm{P}\right]$ orthophosphate. The levels of GDP and GTP bound to ARF6 were assessed as described by Langille et al. (27). As shown in Fig. 1E, cells treated with bombesin or EGF exhibited higher levels of ARF6-GTP than untreated cells.

Bombesin-induced movement of ARF6 to the cell surface is regulated by Goq. Since bombesin had the most potent effect on the translocation of ARF6 to the cell surface, we investigated further the effects of this stimulus on ARF6 distribution. Heterotrimeric $\mathrm{G}$ proteins are likely candidates to play a role in bombesin-induced activation of ARF6. Studies have indicated that bombesin is a Gq-coupled agonist (55), although bombesin activation of PLC $\beta$ in rat acinar cells involved Goi3 (43). To determine whether Gq or Gi3 played a role in ARF6 activation, we coexpressed the activated mutant forms of G $\alpha \mathrm{q}$, G $\alpha q(R 183 C)$, and Gi, Goi3(Q204L), with wild-type ARF6. While coexpression of active Gai3 with ARF6 had no effect on the distribution of either GTPase, the coexpression of activated $\mathrm{G} \alpha \mathrm{q}$ with wild-type ARF6 resulted in the redistribution of ARF6 and Gq to overlapping sites at the cell surface (Fig. 2). When expressed alone, activated Gq labels the cell surface and exhibits a punctate distribution with more intense labeling seen in the perinuclear region (data not shown). To further assess whether Gq mediates bombesin-induced ARF6 activation, we examined the effects of RGS2 on ARF6 distribution and actin rearrangements. RGS (regulators of G-protein signaling) proteins have been shown to exhibit GAP (GTPaseactivating protein) activity by accelerating GTP hydrolysis of $\mathrm{G} \alpha$ subunits $(7,14)$. RGS2 has been shown to function as a GAP for G $\alpha \mathrm{q}$ and to down regulate Gq signaling (19). We have found that coexpression of RGS2 with ARF6 significantly decreased the bombesin-induced redistribution of ARF6 to the plasma membrane (Fig. 2) and hence ARF6-mediated actin remodeling (data not shown). In contrast, coexpression of RGS2 with ARF6(Q67L), the ARF6-GTP mutant, had no effect on ARF6(Q67L)-mediated actin rearrangements (data not shown). Taken together, these data suggest that Gq may function as an upstream regulator of ARF6 activation.

Translocation of vesicle-associated ARF6 and Rac1 to the plasma membrane is regulated by ARF6. Ridley and Hall have previously shown that in Swiss 3T3 cells, bombesin induced membrane ruffling via the activation of Rac1 (48). More recently, ARF6 and Rac1 have been shown to colocalize in perinuclear compartments in HeLa cells, and treatment with AlF induced the redistribution of ARF6 and Rac1 to the cell surface (46). These findings prompted us to examine the distribution of Rac1 in bombesin-treated cells. We began these investigations by first examining the distribution of Rac1 relative to ARF6 in CHO cells. Cells were transfected with plasmids encoding wild-type ARF6 and wild-type Rac1, were fixed, were labeled for ARF6 and Rac1, and were examined by indirect immunofluorescence microscopy. Notably, wild-type Rac1 exhibited labeling in membrane-bound compartments and diffuse labeling in the cytosol of $\mathrm{CHO}$ cells, in contrast to the exclusive membrane-bound distribution of wild-type Rac1 previously reported in HeLa cells (46). Membrane-bound Rac1 localized to the plasma membrane and to intracellular vesicles at the perinuclear region that partially overlapped with ARF6positive perinuclear vesicles (Fig. 3). Wild-type Rac1 alone exhibited a labeling pattern similar to that observed on coexpression with ARF6 (data not shown), indicating that ARF6 expression did not influence the subcellular distribution of Rac1. Next, we investigated whether the distribution of Rac1 was altered in response to bombesin stimulation. Analysis by indirect immunofluorescence of the distribution of Rac1 in bombesin-treated cells transfected with wild-type Rac1 revealed that the majority of the Rac1 label was present on the plasma membrane, particularly at the edges of the lamellipodia with little or no labeling seen in intracellular compartments (Fig. 4). These results imply that bombesin treatment resulted in the redistribution of vesicle-associated Rac1 to the leading edge of the plasma membrane.

Since ARF6 and Rac1 colocalized on intracellular vesicles and at the cell surface on bombesin treatment, we examined whether Rac1 translocation to the plasma membrane was influenced by the ability of ARF6 to promote membrane recycling. Cells cotransfected with wild-type Rac1 and the dominant negative mutant of ARF6, ARF6(T27N), did not exhibit cytoskeletal rearrangements on treatment with bombesin (data not shown). Double labeling for ARF6 and Rac1 in these cells revealed that both GTPases exhibited labeling in a perinuclear vesicle compartment similar to that observed in untreated cells (Fig. 4C and D). Thus, coexpression of the dominant interfering mutant of ARF6 prevented the bombesin-induced redistribution of Rac1 to the cell surface by inhibiting the translocation of ARF6- and Rac1-positive endosomal vesicles to the plasma membrane. In a previous study, we showed that ARF6 (T27N) did not inhibit cytoskeletal rearrangements mediated by $\operatorname{Rac} 1(\mathrm{G} 12 \mathrm{~V})$, the constitutively active and plasma-membrane-associated Rac1 mutant. In support of this observation, 
ARF6

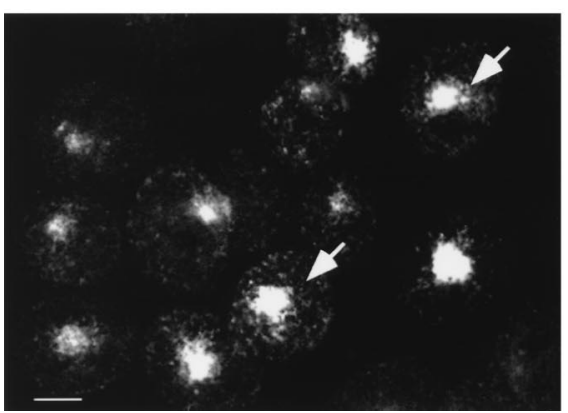

Rac

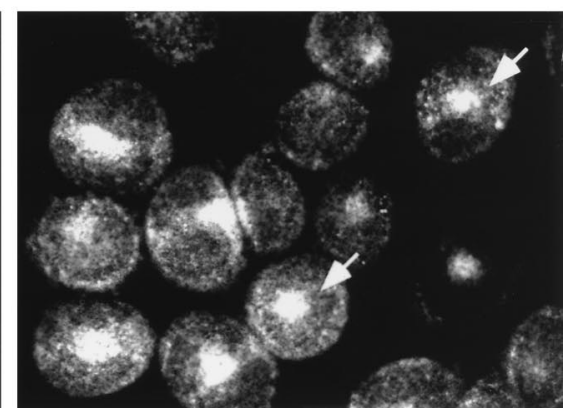

FIG. 3. Overlapping subcellular distribution of ARF6 and Rac1 in CHO cells. Cells coexpressing wild-type ARF6 and Rac1 were fixed and processed for immunofluorescence by using affinity-purified antibodies against ARF6 and Rac1. ARF6 localizes predominantly to the perinuclear region of the cell. Rac1 colocalizes with ARF6 in perinuclear vesicles (arrows) but also exhibits a diffuse cytosolic staining and plasma membrane labeling.

we have also found that coexpression of ARF6(T27N) had no effect on membrane ruffling mediated by C1199Tiam1, the constitutively active and plasma-membrane-localized mutant of the Rac1-GEF, Tiam 1 (data not shown). This supports the contention that ARF6 promotes bombesin-induced cytoskeletal rearrangements by regulating the recruitment of vesicleassociated Rac1 to the cell surface and does not function in a linear pathway downstream of Rac1 activation. Taken together, the studies described here suggest that ARF6 activation serves to couple membrane traffic with the organization of the actin cytoskeleton and provides a role for endosomal membrane recycling in Rac1 activation and membrane ruffling.

ARF6 has no effect on bombesin-induced MAPK activation or EGF and RacG12V-induced JNK activation. In addition to rearrangements of the cortical actin cytoskeleton, bombesin has also been shown to induce the activation of MAPK (5). Since bombesin treatment led to the redistribution and activation of ARF6, we investigated whether ARF6 activation played a role in bombesin-induced activation of MAPK. Towards this end, $\mathrm{CHO}$ cells were cotransfected with either empty vector or a mammalian expression vector expressing ARF6(T27N) and a plasmid encoding HA-tagged MAPK. The transfected cells were serum starved and were treated with bombesin at a concentration of $0.2 \mu \mathrm{M}$. MAPK activity was assayed in immunoprecipitates by using myelin basic protein (MBP) as substrate. As shown in Fig. 5A (right panel), bombesin triggers MAPK activation; however, expression of ARF6(T27N) had no effect on bombesin-induced MAPK activation. Furthermore, expression of the constitutively activated mutant ARF6(Q67L) had no significant effect on MAPK activation when compared to that observed on expression of $\operatorname{Ras}(\mathrm{G} 12 \mathrm{~V})$, a positive control used in the assay (Fig. 5A, left panel). Taken together, our findings indicate that bombesin-stimulated MAPK activation is not mediated by ARF6; however, membrane recruitment and activation of ARF6 is required for bombesin-induced peripheral cytoskeletal rearrangements.

As described above, we observed that translocation of vesicle-associated ARF6 and Rac1 to the plasma membrane occurs in response to physiological stimuli such as the presence of bombesin or EGF and that this process is dependent on ARF6-
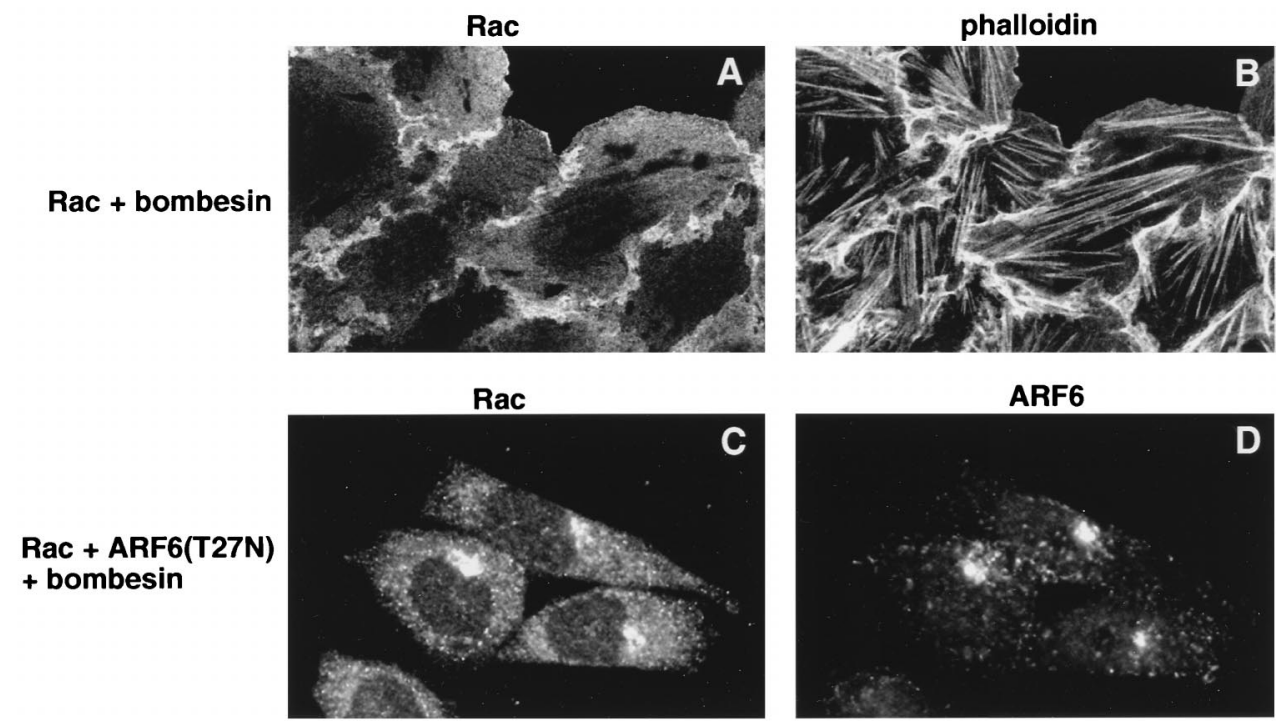

FIG. 4. Bombesin-induced redistribution of Rac1 to the plasma membrane is inhibited by ARF6(T27N). Cells expressing wild-type Rac1 (A and B) or Rac1 plus ARF6(T27N) (C and D) were treated with $15 \mathrm{nM}$ bombesin for $15 \mathrm{~min}$ at $37^{\circ} \mathrm{C}$ and were fixed and processed for indirect immunofluorescence. Cells expressing Rac1 were labeled with anti-Rac1 monoclonal antibody (A) and with rhodamine phalloidin (B). Cells coexpressing Rac1 and ARF6(T27N) were labeled with anti-Rac1 monoclonal antibody (C) and anti-ARF6 rabbit polyclonal antibody (D). As shown, Rac1 localized to the lamellipodia induced on bombesin treatment. Note the formation of stress fibers in the cells. Coexpression of ARF6(T27N) prevents the redistribution of Rac1 to the plasma membrane upon bombesin treatment. 


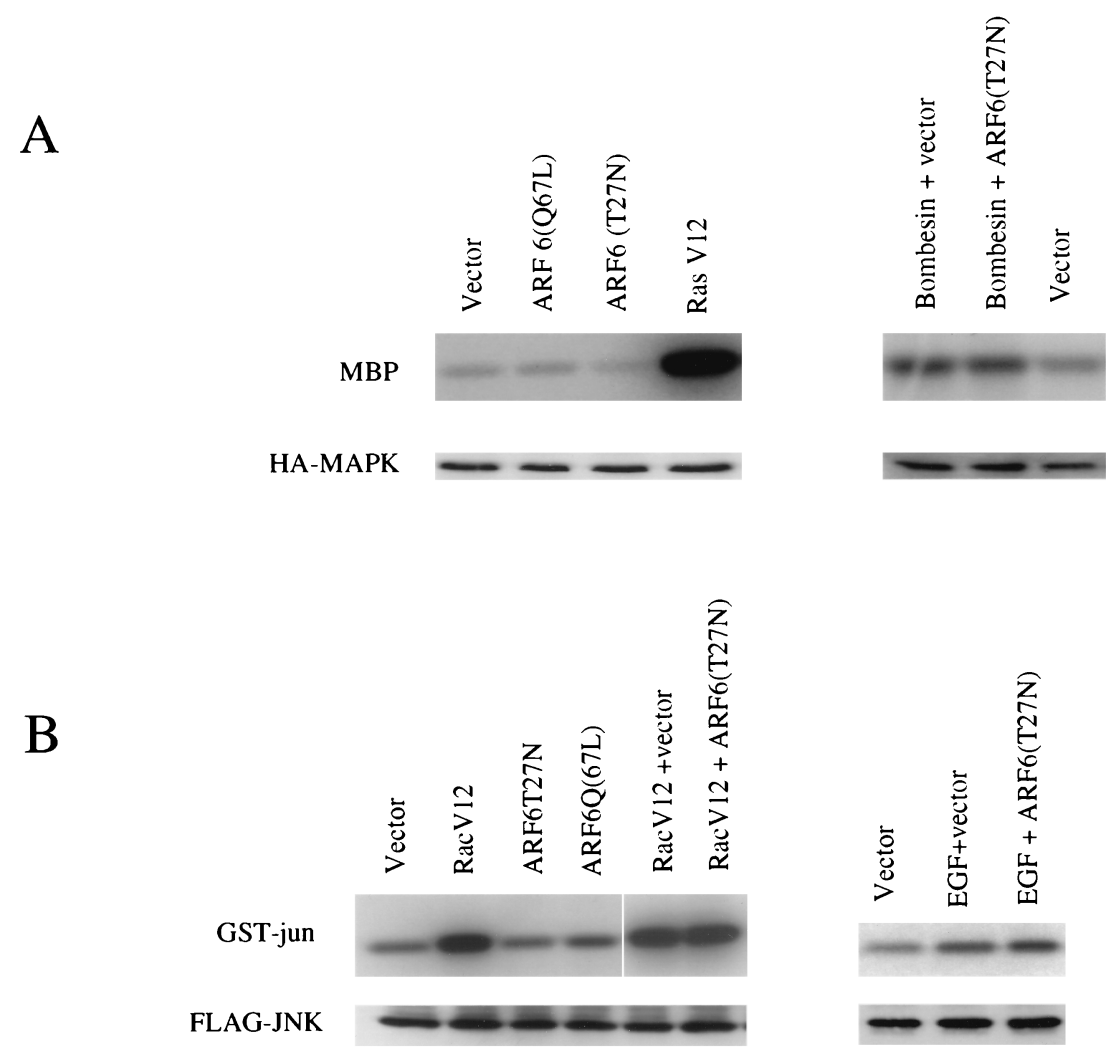

FIG. 5. (A) Effects of ARF6 on MAPK kinase activity. CHO cells were cotransfected with $5 \mu \mathrm{g}$ of HA-tagged MAPK and $5 \mu \mathrm{g}$ of the indicated constructs. Cells in lanes 1 and 2 were treated with bombesin $(0.2 \mu \mathrm{M})$. HA-tagged MAPK was isolated from cell lysates by immunoprecipitation with anti-HA monoclonal antibody 12CA5, and MAPK activity was measured in an immunocomplex kinase assay with MBP as a substrate. Radioactivity incorporated into MBP was visualized by autoradiography. Expression of MAPK was determined by protein immunoblot analysis by using anti-HA antibodies and was found to be similar in each sample. (B) Effects of ARF6 on JNK activity. CHO cells were cotransfected with $5 \mu \mathrm{g}$ of HA-tagged-JNK1 and $5 \mu \mathrm{g}$ of the indicated constructs. Cells in lane 2 and 3 were treated with EGF $(50 \mathrm{ng} / \mathrm{ml})$. JNK activity was measured by immunocomplex kinase assays using GST-Jun as substrate and was visualized by autoradiography. Expression of JNK1 was determined by Western blot analysis by using anti-HA antibodies and was found to be similar in each sample.

mediated membrane recycling. We were interested in determining whether this recycling of endosomal ARF6 played a role in other biological activities mediated by Rac1, in addition to cytoskeletal rearrangements. It has been previously reported that the activation of JNK by EGF is in part mediated by Rac1 (34). Hence, we tested the involvement of ARF6 in EGFRac1-stimulated JNK activation. CHO cells were cotransfected with either empty vector or a mammalian expression vector expressing ARF6(T27N) and a plasmid encoding HA-tagged JNK. The transfected cells were serum starved and treated with EGF at a concentration of $50 \mathrm{ng} / \mathrm{ml}$. JNK activity was assayed by using GST-c-Jun as substrate. Cotransfection with the ARF6(T27N) construct did not inhibit the activation of HAJNK by EGF (Fig. 5B; right panel). Furthermore, coexpression experiments with ARF6(T27N) and Rac1(G12V) revealed that ARF6(T27N) had no effect on Rac(G12V)-induced JNK activation (Fig. 5B, left panel). Expression of ARF6(Q67L) did not result in a significant increase in JNK activation in $\mathrm{CHO}$ cells although a small, but consistent, increase in JNK activation was observed when ARF6(Q67L) was expressed in other cell lines such as 293 cells (data not shown). Nevertheless, in the latter cell type, ARF6(T2N) had no effect on EGF- or Rac(G12V)-induced JNK activation (data not shown). The above findings imply that ARF6 is not involved in EGF-Rac1mediated JNK activation and that the requirement of ARF6activation for Rac1 function appears to be restricted to cellular phenomena (such as bombesin-EGF-triggered cytoskeletal re- arrangements) that necessitate the movement of vesicle-associated ARF6 and Rac1 to the plasma membrane. Moreover, these findings also imply that other ARF6-independent mechanisms exist for Rac1 activation.

Activation of ARF6 antagonizes Rho function. As seen in Fig. 1, the activation of ARF6 by extracellular stimuli induces peripheral cytoskeletal rearrangements that are accompanied by a significant decrease in stress fibers. Consistently as previously described (9), the expression of activated ARF6, ARF6 (Q67L), resulted in a depletion of stress fibers (Fig. 6). We were interested in determining whether this effect of ARF6 activation on stress fibers was correlated with the activity of RhoA. Hence, we examined the effect of LPA, the major serum component shown to induce stress fiber formation via the activation of RhoA (35), on cells expressing activated ARF6. We have found that quiescent $\mathrm{CHO}$ cells expressing ARF6 (Q67L) resisted the formation of stress fibers in response to treatment with LPA (Fig. 6). In contrast, untransfected cells exhibited stress fibers within minutes after treatment with LPA. On more prolonged treatment of ARF6-transfected cells with LPA, formation of stress fibers was followed by cell rounding. These findings prompted us to investigate the effects of ARF6(Q67L) expression on the cellular levels of Rho-GTP in response to LPA. For these studies, we used an in vitro binding assay described by Ren et al. (47) which utilizes the RBD of the Rho effector protein, rhotekin, that interacts exclusively with GTP-bound Rho. The RBD of rhotekin was 

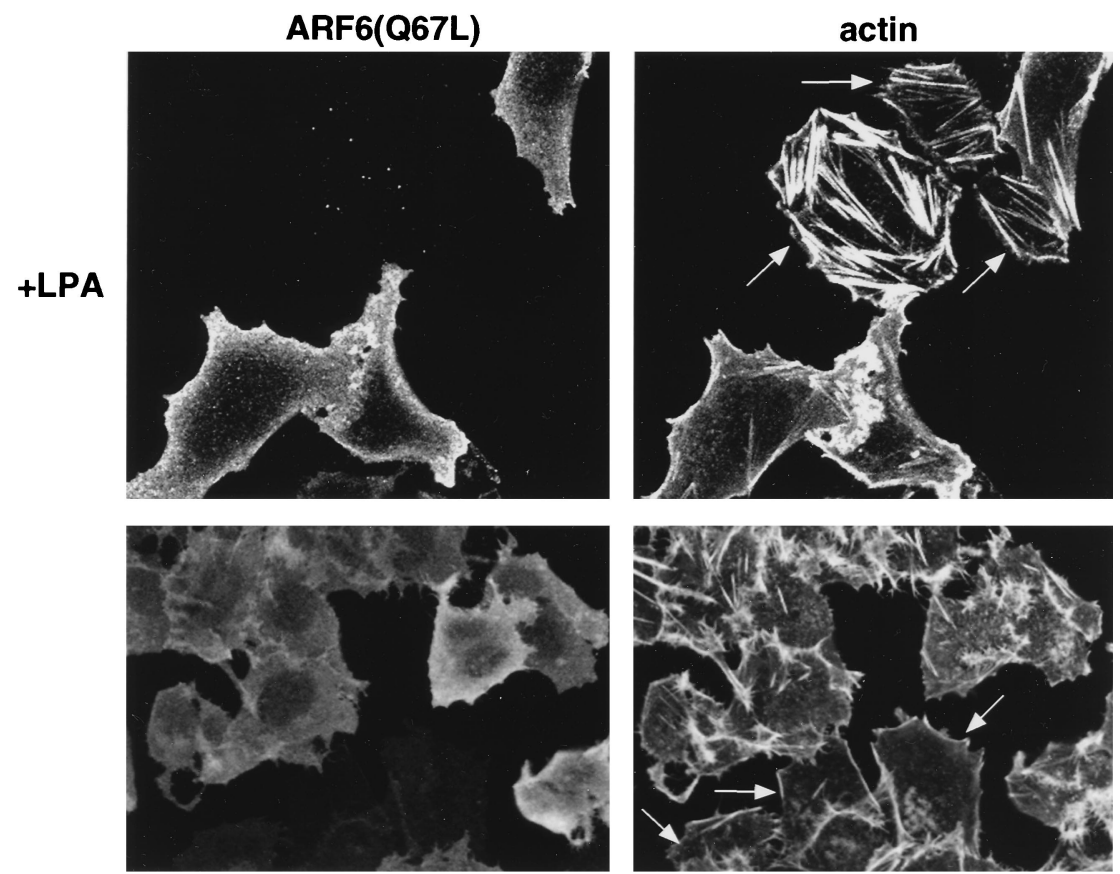

FIG. 6. Effect of LPA treatment on stress fiber formation in ARF6(Q67L)-expressing cells. ARF6-expressing serum-starved cells were treated with $1 \mu \mathrm{M}$ LPA for $10 \mathrm{~min}$ at $37^{\circ} \mathrm{C}$ and were fixed and labeled with anti-ARF6 antibodies and phalloidin. ARF6(Q67L)-expressing cells were resistant to stress fiber formation, whereas untransfected cells (arrow) exhibited stress fibers in response to LPA.

expressed and purified as a GST-fusion protein and was immobilized on glutathione-Sepharose. Lysates of cells mock transfected or transfected with ARF6(Q67L), with and without LPA treatment, were passed over RBD-GST-Sepharose resin, and bound Rho-GTP was assessed by SDS-PAGE followed by immunoblot analysis with anti-RhoA antibody. As seen in Fig. 7, the dramatic increase in the levels of Rho-GTP that is observed on treatment with LPA was not observed in the presence of ARF6(Q67L). ARF6(Q67L) expression or LPA treatment had no effect on the expression levels of Rho. These observations suggest that activation of ARF6 antagonizes the activation of RhoA induced by LPA. Thus, the activation of ARF6 induces a down regulation of Rho function which results in a depletion of stress fibers. In untreated cells, however, expression of ARF6(Q67L) did not appear to have a significant effect on Rho-GTP levels, although stress fiber formation was inhibited. Thus, in addition to down regulating RhoA activation in response to extracellular stimulus, it is possible that ARF6 may have an effect on actin-myosin complex assembly required for stress fiber formation, independent of down regulation of Rho activation.

We then examined whether RhoA could induce actin stress fibers in ARF6-expressing cells. Towards this end, mammalian expression plasmids encoding an activated mutant of Rho, Rho(G14V), and ARF6(Q67L) were cotransfected into CHO cells, and actin filament distribution was visualized by staining with rhodamine phalloidin. As shown in Fig. 8, in comparison with cells expressing ARF6(Q67L) alone (panel B), abundant stress fibers were observed in addition to peripheral rearrangements in cells expressing both ARF6(Q67L) and Rho(G14V) (panel C). Thus, the ARF6-induced inhibition of stress fiber formation was overcome by coexpression of Rho(G14V). Expression of Rho(G14V) alone induced the formation of abundant stress fibers without any effect on surface actin rearrangements (data not shown). Coexpression of ARF6(T27N) had no effect on the formation of stress fibers induced by RhoA (data not shown). However, microinjection of the exoenzyme C3 transferase, an inhibitor of endogenous Rho function, with ARF6(Q67L) did not inhibit ARF6(Q67L)-induced actin rearrangements at the cell surface (Fig. 8). As shown in Fig. 8C and D, microinjected cells (labeled with anti-ARF6) exhibited prominent surface actin rearrangements and a depletion of stress fibers. Microinjection of C3 transferase alone led to the dissolution of stress fibers and had no significant effect on peripheral actin distribution (data not shown). Thus, inhibition of endogenous Rho function had no effect on ARF6-induced actin remodeling.

\section{DISCUSSION}

In this study, we have documented an essential role for ARF6 in membrane recycling and surface remodeling in response to physiological stimulus and in the down regulation of stress fiber formation. While ARF6 and Rac1 cooperate to

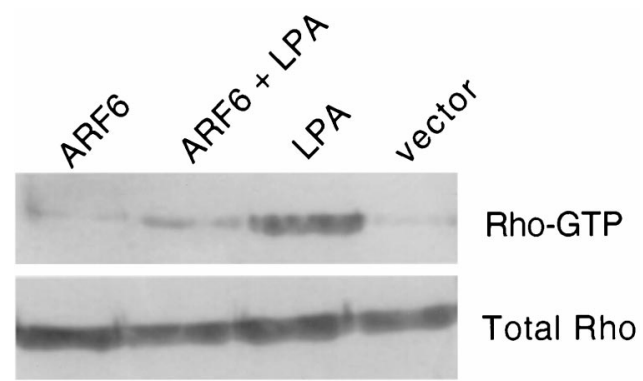

FIG. 7. Binding of Rho-GTP to RBD-GST. Lysates of cells transfected with expression plasmids encoding indicated proteins were incubated with RBD-GST, and bound Rho-GTP was analyzed by Western blotting with anti-RhoA polyclonal antibodies (upper panel). Cells lysates were resolved in SDS gels and were immunoblotted for total Rho with anti-RhoA antibodies (lower panel). 


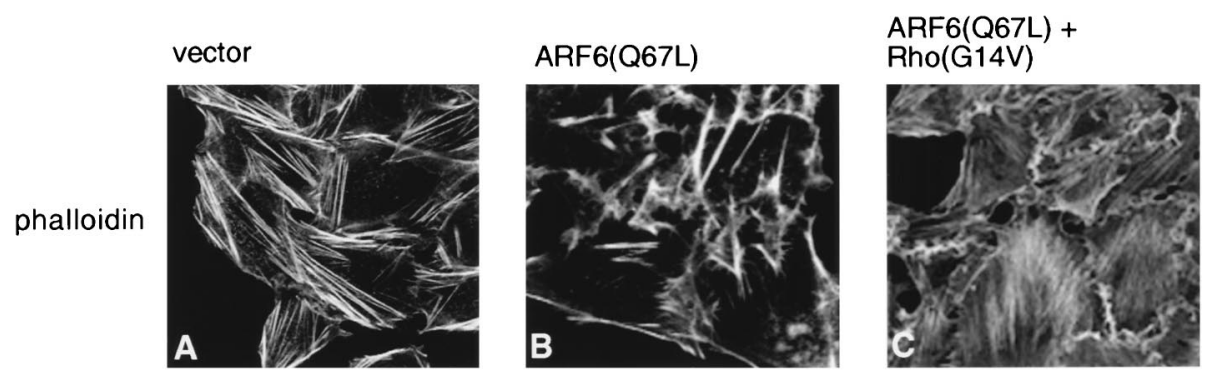

ARF6(Q67L) + C3 transferase

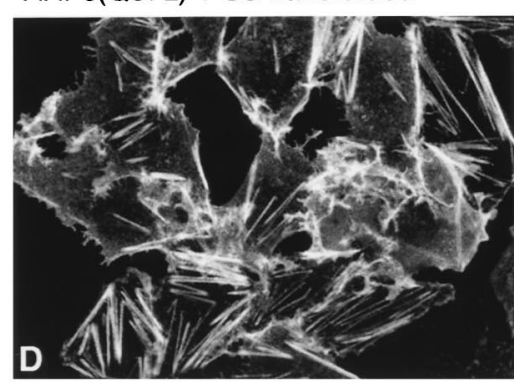

phalloidin

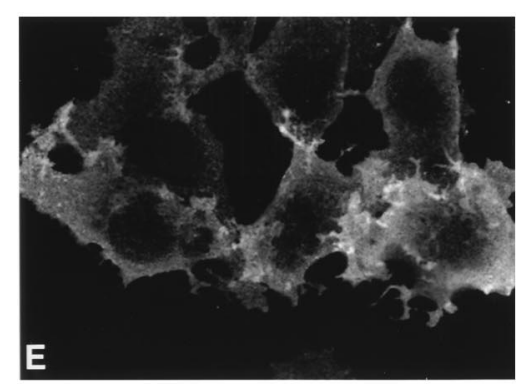

anti-ARF6

FIG. 8. Effect of Rho(G14V) and C3 transferase on ARF6(Q67L)-mediated cytoskeletal rearrangements. Untransfected cells (A), cells transfected with ARF6 (Q67L) (B), cells cotransfected with ARF6(Q67L) and Rho(G14V) (C), or cells microinjected with 0.3 mg of myrARF6(Q67L) per ml and 100 $\mu$ g of C3 transferase per $\mathrm{ml}(\mathrm{D}$ and $\mathrm{E})$ were fixed and labeled with rhodamine phalloidin to visualize actin filament distribution. Rho(G14V) induces stress fiber formation in ARF6 (Q67L)-expressing cells, and C3 transferase did not inhibit ARF6-mediated cytoskeletal rearrangements. Identification of microinjected cells was confirmed by labeling with affinity-purified anti-ARF6 rabbit polyclonal antisera (E).

induce cortical actin rearrangements at the cell surface (in response to bombesin), ARF6 down regulates RhoA activation, resulting in an inhibition of stress fiber formation. Our findings are consistent with roles for ARF6, Rac1, and RhoA in the coordinated regulation of actin filament organization.

The GTPases ARF6 and Rac1 regulate actin remodeling and membrane traffic at the cell periphery (54). In this study, we have shown that treatment of CHO cells with the extracellular agonist bombesin, a bioactive peptide that has been implicated in regulated secretion (50) and cell motility $(1,33)$, resulted in increased cellular levels of ARF6-GTP which were accompanied by the redistribution of ARF6 to the plasma membrane and peripheral actin rearrangements. This process was inhibited by ARF6(T27N), the dominant negative mutant of ARF6. These data imply that bombesin is a bone fide physiological trigger of ARF6 activation.

The molecular chain of events linking bombesin to ARF6 activation remains to be defined. However, one major player involved appears to be the heterotrimeric $\mathrm{G}$ protein, Gq. We found that the effect of bombesin on translocation of wild-type ARF6 to the plasma membrane can be mimicked by the expression of activated G $\alpha$ q. Furthermore, we demonstrated that ARF6 redistribution to the cell surface was inhibited by expression of RGS2, a GAP for Gq that down regulates Gq signaling. These observations have led us to conclude that $\mathrm{Gq}$ is an upstream regulator of bombesin-induced ARF6 activation. How Gq activates ARF6 remains to be investigated. One possible model is that bombesin induces the activation of $\mathrm{G} \alpha \mathrm{q}$, which in turn activates ARF6 via an ARF6-specific guanine nucleotide exchange factor (GEF) such as EFA6 (12), which then induces the redistribution of the ARF6-positive endosomal compartment to the plasma membrane. More recently it has been shown that activation of RhoA by LPA can be mimicked by activated G $\alpha 12$ and G $\alpha 13$ in neuronal cell lines (24). Furthermore, LPA has been shown to activate the Rho exchange factor $\mathrm{p} 115$ via the activation of $\mathrm{G} \alpha 13(17,22)$. Activated $\mathrm{G} \alpha 13$ was demonstrated to interact with p115 and promoted its ability to catalyze nucleotide exchange on Rho. It will be of interest to determine whether a similar mechanism exists for ARF6 activation.

In addition to its effect on cytoskeletal rearrangements, bombesin has also been shown to trigger MAPK activation. However, our results show that bombesin-induced MAPK activation is independent of ARF6. Therefore, bombesin-mediated activation of MAPK and cytoskeletal rearrangements occur via distinct pathways.

Since bombesin has previously been shown to trigger Rac activation, resulting in the formation of membrane ruffles and lamellipodia, we were interested in investigating whether the bombesin-induced activation of ARF6 and Rac1 were linked. We have shown that Rac1 partially overlaps with ARF6 on perinuclear vesicles that are redistributed to the plasma membrane on bombesin treatment. This recruitment of Rac1 to the membrane was dependent on ARF6, since a dominant negative mutant of ARF6 interfered with this event. These studies provide a new model for bombesin-induced Rac1 activation, involving ARF6-regulated endosomal recycling. At the plasma membrane, activated ARF6 and Rac1 elicit distinct local changes that result in cortical actin rearrangements. It is likely that a balance between the activities of the ARF6 and Rac1 GTPases at the plasma membrane will determine the overall morphology of the cell.

The model described above ascribes a role for membrane traffic in the formation of actin rearrangements at the cell periphery. We had previously shown that ARF6(T27N), the dominant negative mutant of ARF6, does not block actin rearrangements induced by $\operatorname{Rac} 1(\mathrm{G} 12 \mathrm{~V})$, the plasma-membrane 
associated, constitutively activated mutant of Rac1 (9). In addition, here we have shown that ARF6(T27N) did not interfere with surface ruffling induced by the activated Rac1-GEF mutant, C1199Tiam. These findings suggest that ARF6 does not influence linear signaling components downstream of Rac1, but aids in the recruitment of Rac1 to the cell surface in response to specific extracellular stimuli. It should be noted, however, that in some other cell types, such as HeLa cells, ARF6(T27N) has been reported to inhibit actin rearrangements induced by activated Rac1 (45). The discrepancy in these observations is unclear and may likely be due to differences that exist in signaling pathways downstream of Rac activation in different cell types.

Although our data clearly indicate a role for ARF6-mediated endosomal recycling in Rac1-mediated actin remodeling, several observations support the contention that other ARF6independent mechanisms may exist for Rac1 activation and its subsequent biological activities. For instance, growth factors such as PDGF that induce membrane ruffling via the activation of Rac1 have no effect on the recruitment of vesicle-associated Rac1 to the plasma membrane, and EGF-Rac1-stimulated JNK activation occurs independently of ARF6. Furthermore, immunoelectron microscopy of cells expressing ARF6(T27N) and wild-type Rac1 have shown that while all of the ARF6 mutant is retained intracellularly, only a subpopulation of Rac1 (approximately 40\%) is sequestered in the ARF6 endosome, whereas $60 \%$ of the Rac1 label is present at the cell surface (P. Peters and C. D'Souza-Schorey, unpublished observations). It is likely that this plasma-membrane-associated Rac1 (as well as cytosolic Rac1) may be activated by other mechanisms and by other agonists that are independent of endosomal membrane recycling and ARF6.

We have also investigated the relationship between ARF6 and Rho. These studies were prompted by our observation that ARF6(Q67L), in addition to actin rearrangements at the cell periphery, also induced a depletion of stress fibers (9). One possible mechanism by which ARF6 exerts an effect on stress fibers is by down regulating RhoA activation. Indeed, we have found that cells expressing ARF6(Q67L) did not exhibit an increase in Rho-GTP levels in response to treatment with LPA, a lysophospholipid abundant in serum that has been shown to induce the formation of stress fibers via the activation of RhoA. Furthermore, stress fibers were readily formed in cells expressing ARF6(Q67L) and the activated Rho mutant Rho(G14V). The molecular mechanism by which ARF6 inhibits Rho activation remains unknown at this point. It is possible that this regulation occurs at the level of Rho regulators, i.e., GEF, GAP, and guanine nucleotide dissociation inhibitor. Interestingly, P190, a Rho GAP, promotes the formation of ruffles and neurite outgrowths in N1E-115 cells, whereas Tiam1-induced activation of Rac1 antagonizes Rho signaling during neurite formation (55).

In the absence of LPA treatment, expression of ARF6 (Q67L) does not appear to have a significant effect on RhoGTP levels. Thus, in addition to down regulating RhoA activation in response to extracellular stimulus, it is possible that ARF6 may have an effect on actin-myosin complex assembly required for stress fiber formation. Recently, p21 adhesion kinase, a downstream effector of Rac1 and Cdc42, has been demonstrated to phosphorylate myosin light chain kinase (an enzyme which phosphorylates myosin light chain), resulting in decreased myosin light chain kinase activity and a loss of stress fibers (51). Furthermore, van Leeuwen et al. have shown that Rac1-regulated phosphorylation of the myosin heavy chain (MHC) in PC12 cells leads to loss of cortical myosin II and cell spreading in PC12 cells (56). Thus, MHC phosphorylation is a yet another mechanism for actin-myosin complex disassembly. It will be interesting to determine whether ARF6(Q67L) induces a rearrangement of stress fibers by altering the phosphorylation status of MHC or myosin light chain. We are investigating the role of ARF6 in stress fiber assembly in $\mathrm{CHO}$ cells.

Membrane ruffles and protrusions are characteristically present at the leading edge of motile cells, whereas stress fibers that promote adhesion to the substratum correlate negatively with cell locomotion. A strict balance between cell adhesion and migration is fundamental to various cellular processes that impinge on motility, such as invasion, axonal outgrowth, diapedesis, chemotaxis, etc. Noteworthy is a recent study by Nobes and Hall which showed that the dominant negative mutant of Rac1 perturbed protrusive events in a wound healing assay, whereas inactivation of Rho kinase, by the Rho kinase inhibitor Y-27632 (52), led to the dissolution of stress fibers and enhanced cell movement during wound healing (40). Given the effect of ARF6 on stress fiber formation and peripheral actin rearrangements, it would be interesting to explore the possibility that ARF6 may promote the wound healing process.

The findings presented in this study are supportive of pivotal roles for ARF6 and the Rho family GTPases in the coordinated regulation of cortical actin changes. The result is a complex but well-controlled interplay of interdependent signaling pathways in which small GTPases couple extracellular signals from cell surface receptors to a spectrum of cellular responses.

\section{ACKNOWLEDGMENTS}

We thank Philip D. Stahl for generous support during the initial stages of this study. We also thank John G. Collard, Frank van Leeuwen, Scott Hoximer, Ken Blumer, Maurine Linder, and Martin Schwartz for providing us with reagents used in this study and Bill Archer for assistance with confocal microscopy.

This work was supported in part by a grant from the American Cancer Society (ACS-IRG 36-39) and by interim support from the University of Notre Dame to C.D.-S. and NIH grant (RO1CA72982OIAI) to L.V.A. C.D.-S. is a Special Fellow of the Leukemia Society of America. L.V.A. is a recipient of a fellowship from the Sidney Kimmel Foundation and the V. Foundation.

\section{REFERENCES}

1. Aprikian, A. G., L. Tremblay, K. Han, and S. Chevalier. 1997. Bombesin stimulates the motility of human prostate-carcinoma cells through tyrosine phosphorylation of focal adhesion kinase and of integrin-associated proteins. Int. J. Cancer 72:498-504.

2. Bretscher, M. S. 1996. Getting membrane flow and the cytoskeleton to cooperate in moving cells. Cell 87:601-606.

3. Bretscher, M. S., and C. Aguado-Velasco. 1998. EGF induces recycling membrane to form ruffles. Curr. Biol. 8:721-724.

4. Brown, H. A., S. Gutowski, C. R. Moomaw, C. Slaughter, and P. C. Sternweiss. 1993. ADP-ribosylation factor, a small GTP-dependent regulatory protein stimulates phospholipase D activity. Cell 75:1137-1144.

5. Charlesworth, A., and E. Rozengurt. 1997. Bombesin and neuromedin B stimulate the activation of $\mathrm{p} 42$ (mapk) and $\mathrm{p} 74($ raf-1) via a protein kinase C-independent pathway in Rat-1 cells. Oncogene 14:2323-2329.

6. Cockroft, S., G. M. H. Thomas, A. Fensome, B. Geny, E. Cunningham, L. Gout, I. Hiles, N. F. Totty, O. Truong, and J. J. Hsuan. 1994. Phospholipase D: a downstream effector of ARF in granulocytes. Science 263:523-526.

7. De Vries, L., and M. Farquhar Gist. 1999. RGS proteins: more than just GAPs for heterotrimeric G proteins. Trends Cell Biol. 9:138-144.

8. D'Souza-Schorey, C., C. Li, M. I. Colombo, and P. D. Stahl. 1995. A regulatory role for ARF6 in receptor-mediated endocytosis. Science 267:11751178 .

9. D'Souza-Schorey, C., R. L. Boshans, M. McDonough, P. D. Stahl, and L. van Aelst. 1997. A role for POR 1, a Rac 1-interacting protein, in ARF6-mediated cytoskeletal rearrangements. EMBO J. 16:5445-5454.

10. D'Souza-Schorey, C., E. van Donselaar, V. Hsu, C. Yang, P. D. Stahl, and P. J. Peters. 1998. ARF6 targets recycling endosomal vesicles to the plasma membrane: insights from an ultrastructural investigation. J. Cell Biol. 140: 603-616.

11. D'Souza-Schorey, C., B. Boettner, and L. van Aelst. 1998. Rac regulates 
integrin-mediated cytoskeletal spreading and increased adhesion of T lymphocytes. Mol. Cell. Biol. 18:3936-3946.

12. Franco, M., P. J. Peters, J. Boretto, E. van Donselaar, A. Neri, C. D'SouzaSchorey, and P. Chavrier. 1999. EFA6, a sec7 domain-containing exchange factor for ARF6, coordinates membrane recycling and actin cytoskeleton organization. EMBO J. 18:1480-1491.

13. Galas, M.-C., J. B. Helms, N. Vitale, D. Thierese, D. Aunis, and M.-F. Bader. 1997. Regulated exocytois in Chromaffin cells. A potential role for a secretory granule associated ARF6 protein. J. Biol. Chem. 272:2788-2798.

14. Guan, K. L., and M. Han. 1999. A G-protein signaling network mediated by an RGS protein. Genes Dev. 13:1763-1767.

15. Hall, A. 1998. Rho GTPases and the actin cytoskeleton. Science 279:509514.

16. Hammond, S. M., Y. M. Altschuller, T. Sung, S. A. Rudge, K. Rose, J. Engebrecht, A. J. Morrise, and M. A. Frohman. 1995. Human ADP-ribosylation factor-activated phosphatidylcholine-specific phospholipase D defines a new and highly conserved gene family. J. Biol. Chem. 270:29640-29643.

17. Hart, M. J., X. Jiang, T. Kozasa, W. Roscoe, W. D. Singer, A. G. Gilman, P. C. Sternweis, and G. Bollag. 1998. Direct stimulation of guanine nucleotide exchange activity of p115 RhoGEF by G $\alpha 13$. Science 280:2112-2114.

18. Hawkins, P. T., A. Eguinoa, R.-G. Qiu, D. Stokoe, F. T. Cooke, R. Walters, S. Wennstrom, L. Claessen-Welsh, T. Evans, M. Symons, and L. Stephens. 1995. PDGF stimulates an increase in GTP-Rac via activation of phosphoinositide 3-kinase. Curr. Biol. 5:393-403.

19. Heximer, S. P., N. Watson, M. E. Linder, K. J. Blumer, and J. R. Helper. 1997. RGS2/G0S8 is a selective inhibitor of Gqalpha function Proc. Natl. Acad. Sci. USA 94:14389-14393.

20. Hopkins, C. R., A. Gibson, M. Shipman, D. K. Strickland, and I. S. Trowbridge. 1994. In migrating fibroblasts, recycling receptors are concentrated in narrow tubules in the pericentriolar area, and then routed to the plasma membrane of the leading lamella. J. Cell Biol. 125:1265-1274.

21. Kahn, R. A., and A. G. Gilman. 1986. The protein cofactor necessary for ADP-ribosylation of Gs by cholera toxin is itself a GTP-binding protein. J. Biol. Chem. 261:7906-7911.

22. Kozasa, T., X. Jiang, M. J. Hart, P. M. Sternweis, W. D. Singer, A. G. Gilman, G. Bollag, and P. C. Sternweis. 1998. p115 RhoGEF, a GTPase activating protein for Galpha12 and Galpha13. Science 280:2109-2111.

23. Kozma, R., S. Ahmed, A. Best, and L. Lim. 1995. The Ras-related protein $\mathrm{Cdc} 42 \mathrm{Hs}$ and bradykinin promote formation of peripheral actin microspikes and filopodia in Swiss 3T3 Fibroblasts. Mol. Cell. Biol. 15:1942-1952.

24. Kranenburg, O., M. Poland, F. P. van Horck, D. Drechsel, A. Hall, and W. H. Moolenaar. 1999. Activation of RhoA by lysophosphatidic acid and Galpha12/13 subunits in neuronal cells: induction of neurite retraction. Mol. Biol. Cell 10:1851-1857.

25. Ktistakis, N., H. A. Brown, M. G. Waters, P. C. Sternweiss, and M. G. Roth. 1996. Evidence that phospholipase D mediates ADP ribosylation factordependent formation of Golgi coated vesicles. J. Cell Biol. 108:2169-2181.

26. Lamaze, C., T. H. Chuang, L. J. Trelecky, G. M. Bockoch, and S. L. Schmid. 1996. Regulation of receptor-mediated endocytosis by Rho and Rac. Nature 382:177-179.

27. Langille, S. E., V. Patki, J. K. Klarlund, J. M. Buxton, J. J. Holik, A. Chawla, S. Corvera, and M. P. Czech. 1999. ADP-ribosylation factor 6 as a target of guanine nucleotide exchange factor GRP1. J. Biol. Chem. 274:27099-27104.

28. Lawson, M. A., and F. R. Maxfield. $1995 . \mathrm{Ca}^{2+}-$ and calcineurin-dependent recycling of an integrin to the front of migrating neutrophils. Nature 377: 75-79.

29. Lenhard, J. M., M. I. Colombo, and P. D. Stahl. 1994. Heterotrimeric GTP-binding proteins and ADP-ribosylation factor regulate priming of endosomal membranes for fusion. Arch. Biochem. Biophys. 312:474-479.

30. Liang, J. O., and S. Kornfeld. 1997. Comparative activity of ADP-ribosylation factor family members in the early steps of coated vesicle formation on rat liver Golgi membranes. J. Biol. Chem. 272:414-418.

31. Massenburg, D., J.-S. Han, M. Liyanage, W. A. Patton, S. G. Rhee, J. Moss, and M. Vaughan. 1994. Activation of rat brain phospholipase D by ADPribosylation factors 1, 5, and 6: separation of ADP ribosylation factor dependent and oleate dependent enzymes. Proc. Natl. Acad. Sci. USA 91: 11718-11722.

32. McGraw, T. E., L. Greenefield, and F. R. Maxfield. 1987. Functional expression of human transferrin receptor cDNA in chinese hamster ovary cells deficient in endogenous transferrin receptor. J. Cell Biol. 105:207-214.

33. Milusheva, E. A., N. I. Kortezova, Z. N. Mizhorkova, M. Papasova, D. H. Coy, A. Balint, E. S. Vizi, and G. Varga. 1998. Role of different bombesin receptor subtypes mediating contractile activity in cat upper gastrointestinal tract. Peptides 19:549-556.
34. Minden, A., A. Lin, F. X. Claret, A. Abo, and M. Karin. 1995. Selective activation of the JNK signaling cascade and c-Jun transcriptional activity by the small GTPases Rac and Cdc42Hs. Cell 81:1147-1157.

35. Moolenaar, W. H., O. Kranenburg, F. F. Postma, and C. C. M. Zondag. 1997. Lysophosphatidic acid: G-protein signalling and cellular responses. Curr. Opin. Cell Biol. 9:168-173.

36. Moss, J., and M. Vaughan. 1995. Structure and function of ARF proteins: activators of cholera toxin and critical components of intracellular vesicular transport processes. J. Biol. Chem. 266:2606-2614.

37. Moss, J., and M. Vaughan. 1998. Molecules in the ARF orbit. J. Biol. Chem. 273:21431-21434

38. Nobes, C. D., and A. Hall. 1995. Rho, Rac and Cdc42 GTPases regulate the assembly of multimolecular focal complexes associated with actin stress fibers, lamelipodia, and filopodia. Cell 81:53-62.

39. Nobes, C. D., P. Hawkins, L. Stephens, and A. Hall. 1995. Activation of GTP-binding proteins Rho and Rac by growth factor receptors. J. Cell Sci. 108:226-233.

40. Nobes, C. D., and A. Hall. 1999. Rho GTPases control polarity, protrusion, and adhesion during cell movement. J. Cell Biol. 144:1235-1244.

41. Norman, J. C., L. S. Price, A. J. Ridley, and A. Koffer. 1996. The small GTP-binding proteins, Rac and Rho, regulate cytoskeletal organization and exocytosis in mast cells by parallel pathways. Mol. Biol. Cell 7:1426-1442.

42. Peters, P. J., V. W. Hsu, C. E. Ooi, D. Finazzi, S. B. Teal, V. Oorschot, J. G. Donaldson, and R. D. Klausner. 1995. Overexpression of wild-type and mutant ARF1 and ARF6: distinct perturbations of nonoverlapping membrane compartments. J. Cell Biol. 128:1003-1017.

43. Pigeon, C., M. Le Romancer, C. Linard, M. J. Lewin, and F. Reyl-Desmars. 1996. Bombesin activation of phospholipase $C$ beta 1 in rat acinar pancreatic cells involves the pertussis toxin-sensitive $G$ alpha i3 protein. Regul. Pept. 62:153-159.

44. Radhakrishna, H., R. D. Klausner, and J. G. Donaldson. 1996. Aluminum fluoride stimulates surface protrusions in cells overexpressing the ARF6 GTPase. J. Cell Biol. 134:935-946.

45. Radhakrishna, H., and J. G. Donaldson. 1997. ADP-ribosylation factor 6 regulates a novel plasma membrane recycling pathway. J. Cell Biol. 139:49-61.

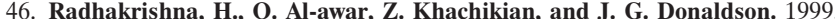
ARF6 requirement for Rac ruffling suggests a role for membrane trafficking in cortical actin rearrangements. J. Cell Sci. 112:855-866.

47. Ren, X. D., W. B. Kiosses, and M. A. Schwartz. 1999. Regulation of the small GTP-binding protein Rho by cell adhesion and the cytoskeleton. EMBO J. 18:578-585

48. Ridley, A. J., and A. Hall. 1992. The small GTP-binding protein Rho regulates the assembly of focal adhesions and actin stress fibers in response to growth factors. Cell 70:389-399.

49. Ridley, A. J., H. F. Paterson, C. L. Johnston, D. Diekman, and A. Hall. 1992. The small GTP-binding protein Rac regulates growth factor-induced membrane ruffling. Cell 70:401-410.

50. Sanders, L. C., F. Matsumara, G. M. Bokoch, and P. de Lanerolle. 1999. Inhibition of myosin light chain kinase by p21 activated kinase. Science 283:2083-2085.

51. Seensalu, R., D. Avedian, R. Barbuti, M. Song, L. Slice, and J. H. Walsh. 1997. Bombesin-induced gastrin release from canine $\mathrm{G}$ cells is stimulated by $\mathrm{Ca}^{2+}$ but not by protein kinase $\mathrm{C}$, and is enhanced by disruption of rho/ cytoskeletal pathways. J. Clin. Investig. 100:1037-1046.

52. Uehata, M., T. Ishizaki, T. Ono, T. Kawahara, T. Morishita, H. Tamakawa, K. Yamagami, J. Inui, M. Maekawa, and S. Narumiya. 1997. Calcium sensitization of smooth muscle mediated by a Rho associated protein kinase in hypertension. Nature 389:990-994.

53. van Aelst, L., T. Joneson, and D. Bar-Sagi. 1996. Identification of a novel Rac1 interacting protein involved in membrane ruffling. EMBO J. 15:37783786.

54. van Aelst, L., and C. D'Souza-Schorey. 1997. Rho GTPases and signaling networks. Genes Dev. 11:2295-2322.

55. van Leeuwen, F., H. E. Kain, R. A. Kammen, F. Michiels, O. W. Kranenburg, and J. G. Collard. 1997. The guanine nucleotide exchange factor Tiam1 affects neuronal morphology; opposing roles for the small GTPases Rac and Rho. J. Cell Biol. 139:797-807.

56. van Leeuwen, F., S. van Delft, H. E. Kain, R. A. van der Kammen, and J. G. Collard. 1999. Rac regulates the phosphorylation of myosin II heavy chain, actinomyosin disassembly and cell spreading. Nat. Cell Biol. 1:242-248.

57. Wang, J. L., S. Kalyanaraman, M. D. Vivo, and N. Gautam. 1996. Bombesin and thrombin affect discrete pools of intracellular calcium through different G-proteins. Biochem. J. 320:87-91. 